\title{
Poesía y don de lenguas: ritmo y noción de significante
}

\author{
Luis Alberto López Soto*
}

Resumen:

En este artículo se establece una relación analógica entre poesía y la práctica extática conocida como "don de lenguas" o glosolalia. A partir de una revisión teórica se conjuga la posibilidad de que, más que modelización secundaria o metalenguaje, la poesía comporte en el ritmo un modelo psíquico de expresión más allá de las imágenes, las metáforas y, por ende, el contenido semántico. Asimismo, se sugiere que esta noción se observa tanto en el substrato religioso premoderno como en ciertas manifestaciones vanguardistas. Esto con el propósito de analizar cómo es que el acto poético implica un plus, un excedente de significante.

Palabras clave:

Ritmo, significante, glosolalia, poesía vanguardista.

La naturaleza del arte literario y la poesía se ha entendido como un metalenguaje o principio de equivalencias (Jakobson, Lingüistica y poética 40), o una estructura que, emanada del lenguaje denotativo, pasa a ser un sistema de segundo orden (Lotman 34). Desde la lingüística estructural, y a partir de la noción de significante, la obra de Ferdinand de Saussure ha constituido todo un paradigma que, en los

\footnotetext{
* Universidad de Sonora.
} 
estudios literarios, se asocia a la "forma", a lo "estético", en oposición dual al "significado", al "sentido", al "contenido." Específicamente respecto al ritmo en la poesía como elemento estructurante y composicional del verso, hay una tendencia teórica consistente en resaltar el carácter preponderante de aquel en la significación, así como una amplia vertiente hermenéutica que observa en la poesía una relación con lo religioso y lo místico.

Es en el diálogo platónico Ion o sobre la poesía donde Sócrates le dice al rapsoda Ion que lo suyo -declamar los hexámetros de Homero- "no es en ti un efecto del arte, sino que es no sé qué virtud divina que te trasporta, virtud semejante a la piedra que Eurípides ha llamado magnética" (195). Es decir, la recitación de versos no es reductible a la técnica, que es a lo que etimológicamente se refiere con arte el texto socrático, ni a un conocimiento científico (la episteme). La recitación de versos se asocia en el pasaje a un estado peculiar de conciencia (o inconsciencia exaltada) alegorizado en la imagen de un imán que, como símbolo de un éxtasis, trasciende o precede aparentemente a la lógica racional. ${ }^{1}$

Un análisis más detenido del pasaje arroja que, en realidad, no estamos sino ante una mera ironía socrática, recurso usado por Platón para descalificar a los poetas y, por ende, a la poesía. Si, para Platón, los poetas son imitadores y por lo tanto inútiles en su proyecto de república, la descalificación consiste en que la figura del rapsoda es la de un ser doblemente imitativo, pues imita a otro imitador por antonomasia, el poeta. Así, al afirmarse que la práctica de Ion no es técnica ni conocimiento, se le recluye a este, más que en lo divino, en el orden de lo irracional y de lo inútil. No obstante, tal diálogo platónico ha pasado a la historia de la filosofía como una indagatoria - una de cuyas hipótesis es la mística y religiosa- sobre la inspiración poética.

Por otra parte, en el contexto bíblico y cristiano, es conocido el pasaje del libro de Hechos de los Apóstoles donde se narra un

${ }^{1} \mathrm{Al}$ respecto, véase Gil, Luis. Los antiguos y la inspiración poética, Guadarrama Ediciones, 1967. 
fenómeno místico conocido como "bautismo en el Espíritu", consistente en que el recitador de oraciones es sumergido en un trance a partir del cual profiere palabras desconocidas que representan una lengua desconocida y angelical que, en teología cristiana, se conoce como glosolalia. ${ }^{2}$ El fenómeno es conocido tanto en el cristianismo como en algunas otras religiones y vertientes del esoterismo. A la luz del pasaje, el creyente adquiere repentinamente la habilidad de orar en lenguas angelicales, es decir, "lenguas" incomprensibles para el ser humano. Ante la acusación de embriaguez, el cristianismo primitivo atribuyó tal evento al "bautismo en el Espíritu", corolario del bautismo en agua de Juan el bautista (Mateo 3:11) y como evidencia de la presencia de Dios en el cuerpo del creyente. Esto se observa en el libro de los Hechos. ${ }^{3}$ La respuesta racionalista

${ }^{2}$ He aquí el pasaje: "Cuando llegó el día de Pentecostés, estaban todos unánimes juntos. $Y$ de repente vino del cielo un estruendo como de un viento recio que soplaba, el cual llenó toda la casa donde estaban sentados; y se les aparecieron lenguas repartidas, como de fuego, asentándose sobre cada uno de ellos. Y fueron todos llenos del Espíritu Santo, y comenzaron a hablar en otras lenguas, según el Espíritu les daba que hablasen. Moraban entonces en Jerusalén judíos, varones piadosos, de todas las naciones bajo el cielo. Y hecho este estruendo, se juntó la multitud; y estaban confusos, porque cada uno les oía hablar en su propia lengua. Y estaban atónitos y maravillados, diciendo: Mirad, ¿no son galileos todos estos que hablan? ¿Cómo, pues, les oímos nosotros hablar cada uno en nuestra lengua en la que hemos nacido? Partos, medos, elamitas, y los que habitamos en Mesopotamia, en Judea, en Capadocia, en el Ponto y en Asia, en Frigia y Panfilia, en Egipto y en las regiones de África más allá de Cirene, y romanos aquí residentes, tanto judíos como prosélitos, cretenses y árabes, les oímos hablar en nuestras lenguas las maravillas de Dios. Y estaban todos atónitos y perplejos, diciéndose unos a otros: ¿Qué quiere decir esto? Mas otros, burlándose, decían: Están llenos de mosto." (Hechos 2: 1-13. Versión Reina-Valera 1960) En este pasaje se observan dos fenómenos distintos y que, por lo tanto, no deben confundirse: el de la glosolalia y la xenoglosia. El primero se refiere a una práctica mística donde el creyente entra en éxtasis y habla en lenguas "angelicales" o desconocidas y el segundo se refiere a que el creyente habla milagrosamente en una lengua humana no aprendida.

${ }^{3}$ A pesar de ser numerosas las referencias donde el texto bíblico relata o describe una situación de éxtasis, no todas las veces se usa en ese sentido extático. Con todo, los teólogos pentecostales usan como base escritural estas partes: I 
y psicoanalítica a este último fenómeno sugiere que hay un trance hipnótico ligero inducido por la autosugestión; que los que hablan en lenguas buscan una regresión a una especie de balbuceo infantil; que se trata de criptomnesia, una especie de memoria oculta y repentinamente exaltada descrita y explicada por Carl Jung. ${ }^{4}$

Para la estética, la teoría literaria o la poética, tales fenómenos extratextuales y tal explicación podrían resultar irrelevantes. Sin embargo, al aunar la imagen del rapsoda magnetizado y la del creyente en trance, puede heurísticamente plantearse la idea de un continum entre cierta noción prelógica del lenguaje y lo único constatable: la noción del significante, esa idea de la materialidad verbal, acústica, acuñada por Ferdinand de Saussure. Pero para el caso que nos ocupa aquí, este significante no se presenta, sin embargo, como una asociación o equivalencia ("la otra cara de la moneda" dicho en términos del adagio popular) con el significado, como se sostiene en el clásico Curso de lingüistica de general, sino como una total instancia determinante que excede a las contingencias semánticas. Asimismo, estas notas a manera de hipótesis sugieren que este significante, o

Corintios 13: 8, I Corintios 14:22-25, I Corintios 14: 18-19, I Corintios 14: 27-28, I Corintios 14:39-40, Hechos 19:6, Marcos 16:17. Los cristianos del primer siglo abandonaron la práctica del don de lenguas: Dios, en su modalidad o persona de Espíritu Santo, se volvió más bien un concepto y no tanto un "viento recio" o fuego lingüístico. A la postre, los teólogos cristianos acuñaron la noción de glosolalia para describir y entender doctrinalmente el éxtasis del llamado don de lenguas. La dispensación del hablar en lenguas, de los milagros, de las profecías, había acabado. Sólo se registra muy esporádicamente ya en la secta de Montano, ya en cierto sector de los cuáqueros. El don de lenguas no reingresó a las iglesias sino hasta principios del siglo XX con el pentecostalismo (el revival de Azusa Street), que dio a su vez lugar al movimiento carismático, llamado así porque estas iglesias hacen énfasis en el karisma (del griego khárisma, que se traduce como don o regalo) el cual tuvo una cierta influencia tanto en la mayoría de denominaciones del protestantismo histórico (luteranos, anglicanos, presbiterianos, bautistas, metodistas et alii) como en el catolicismo, léase catolicismo renovado. $\mathrm{Al}$ respecto de la reinserción de la glosolalia al cristianismo, véase Hollenwegger J., Walter. Elpentecostalismo: historia y doctrinas, Editorial La Aurora, 1976.

${ }^{4}$ Cf. Babcox, Neil. En busca de la realidad carismática, Ediciones las Américas, 1987. 
más bien, esta idea de significante -en tanto que enmarcado en una modalidad poética-, no puede sino presentarse como un discurrir sonoro asociado inherentemente a ciertas asociaciones de ritmo. Así, al contrario de Ricoeur sobre el símbolo como un discurso con excedente de sentido, en este planteamiento la poesía sería un discurso con excedente de significante y ritmo, lo cual paradójicamente constituiría su sentido mismo.

El primer acercamiento a la relación analógica entre poesía y don de lenguas la hace Octavio Paz en un ensayo de 1982 reunido posteriormente en Sombras de obras donde, de manera general, establece que la poesía connota cierta función extática que colinda, por lo tanto, con ciertas implicaciones, experiencias sagradas y espirituales (Paz, "Hablar y decir" 5). Paz analiza el caso de Vicente Huidobro y, a partir de este, deduce que la poesía creacionista (léase, Altazor) realiza una victoria del ser sobre el sentido, de lo indecible sobre el lenguaje. La "insignificancia” (es decir, palabras asignificantes, plenas de vocales) de la última parte del poema de Huidobro es, en suma, la alegoría del fracaso de la voz lírica exploradora de las posibilidades lingüísticas frente a la totalidad del ser. Y no obstante tal fracaso filosófico, la estética aquí implicada, más que asignificante como sugiere Paz, resulta más bien en una visión redundante donde las vocales ( $a$, i) configuran en el poema de Huidobro un patrón sonoro: "Al aia aia / ia ia ia aia ui / Tralalí / Lali lalá / Aruaru / urulario / Lalilá” (109) ¿Cómo leer, es decir, cómo abordar empíricamente e interpretar estos versos que parecen transgredir o trascender todo código? Una lectura inmanentista parecería resultar, en este caso, improcedente, ya que, por definición, todo interpretar es fundamentalmente una búsqueda del sentido y, a su modo, una reducción a categorías pragmáticas: al carecer de núcleo semántico, resulta inútil buscar una referencia que haga inteligibles los versos anteriormente citados. De ahí que Paz recurra a una lectura trascendente, apelando a una noción más bien alegórica para explicar filosófica y estéticamente la función y el sentido de estos versos al final del poema.

A su vez, la crítica italiana Fiorenza Lipparini ha hecho un primer acercamiento a la relación entre glosolalia y la poesía para re- 
ferirse específicamente a la poesía moderna de raigambre simbolista y vanguardista (Mallarmé, Hugo Ball y Antonin Artaud). En tal acercamiento Lipparini interpreta esta relación como la de una vuelta a un lenguaje sagrado constituido, a su vez, por una secular nada metafísica.

Más recientemente hallamos una perspectiva parecida en un trabajo de Víctor Toledo, para quien el acto poético puede entender como un acto de sincronicidad, es decir, de conexión con otras latencias, entre ellas, las de lo sagrado, lo místico, lo musical, lo vibratorio, e incluye además ciertas nociones de la física teórica contemporánea como la teoría de cuerdas en fenómenos específicos como el estado vibratorio del universos.

Así, trascendencia metafísica del ser sobre el lenguaje, vuelta al lenguaje sagrado y sincronicidad vibratoria, cabe articular estas interpretaciones y volver a un aspecto formal y estructurante que, en tanto que elemento composicional, implica el ritmo.

Tradicionalmente, como afirma Helena Beristáin, este se había asociado al nivel sintáctico-fonológico de la lengua, que, de algún modo, permea el sentido (447). No obstante, según las aportaciones de Samuel Gili Gaya sobre el ritmo en la poesía en verso libre o contemporánea, "no es indispensable que sea acústico, fonético, basado en la repetición de acentos o agrupaciones", pues "revivir ciertas representaciones, imágenes o estados afectivos a lo largo del poema, puede producir efectos de recurrencia tan densos como los que se obtienen con la rima, los pies, los acentos fijos." (Gili Gaya 55) Tenemos, pues, que hemos pasado del ritmo prosódico al ritmo semántico y, de ahí, al sentido. Y de ahí al ritmo como una "visión de mundo" (Paz, El arco 59) según teorizaría el mismo Paz en su clásico El arco y la lira, donde leemos la siguiente analogía:

Si se golpea un tambor a intervalos iguales, el ritmo aparecerá como tiempo dividido en porciones homogéneas. La representación gráfica de semejante abstracción podría ser la línea de rayas: ---------- La intensidad rítmica dependerá de la celeridad con que los golpes caigan sobre el parche del tambor. A intervalos más reducidos corresponderá redoblada 
violencia. Las variaciones dependerán también entre golpes e intervalos. Por ejemplo: -I--I-I--I-I--I-I-I --, etc. Aun reducido a ese esquema, el ritmo es algo más que medida, algo más que tiempo dividido en porciones. La sucesión de golpes y pausas revela una cierta intencionalidad, algo así como una dirección. El ritmo provoca una expectación, suscita un anhelar. Si se interrumpe, sentimos un choque. Algo se ha roto. Si continúa, esperamos algo que no acercamos a nombrar. El ritmo engendra en nosotros una disposición de ánimo que sólo podrá calmarse cuando sobrevenga "algo". (56-57)

En esta analogía musical, Paz encuentra un modelo empírico con el cual intenta exponer las modulaciones verbales motivadas por asociaciones semánticas, al menos desde el punto de vista de la percepción. Estas modulaciones verbales no son sino las variaciones acentuales y temáticas. En ese "algo" subyace un sentido plenamente significativo generado por el fenómeno inasible conocido como entonación, que trasciende la conjunción sincopada de los "golpes" y "pausas". Este sentido repercute en todo un hallazgo sensorial que, para Paz, se revela en "cierta intencionalidad, algo así como una dirección”, capaz de expresar y comunicar -o connotarcasi al mismo grado que el contenido puro o manifiesto. Se vuelve cierta la máxima formalista de que el medio (la materialidad del signo y sus efectos acústicos) es el mensaje, a la vez que la palabra poética recupera su origen preponderantemente oral que connota cierta atmósfera de ritualidad. De ahí que en el modelo de Paz este utilice como figura la del tambor, símbolo asociado a una especie de edad primitiva en la que la historia carece de una visión lineal y el tiempo no es sino un fluir denso, solo interrumpido por la concesión de la pausa.

Asimismo, y siguiendo con esta perspectiva algo orgánica, tenemos la definición de Antonio García Berrio, para quien el ritmo poético es

la creación artificial de series regularmente sucesivas de elementos recurrentes, que se corresponden con la seriación ar- 
mónica de los ritmos vitales, creando cadencias de identificación (invariantes) y de diferencia (variaciones), agrupadas en unidades de organización extensa, que reconocemos como textos u obras. (García Berrio 90)

Los casos analizados y comentados por Antonio García Berrio son Rubén Darío y Federico García Lorca, en los cuales observa, amén de los elementos constructivos implicados en el ritmo técnico, una aspiración de "ritmo de ideas" (102) asequible a partir de la modernidad poética. A la luz de lo expuesto en esta nota, salta a la vista la noción de un patrón binario o dual como modelo teórico. Esta concepción de ritmo, que más adelante García Berrio denomina biorritmos, se asocia a los movimientos corporales como la respiración, latidos cardíacos, etc., y queda, pues, como la expresión estilizada de un orden natural biológico y cuya función y sentido es básicamente imitativo. El orden poético sería, por así decirlo, un signo vehicular que funciona como extensión de los ritmos o ciclos naturales.

A la luz de toda esta conceptualización, ¿cómo se relaciona el ritmo en tanto que tal (es decir, como recurrencia) con el fenómeno de la glosolalia como potencial numen poético?

Un primer indicio de esta relación puede rastrearse en la jitanjáfora, ese recurso estudiado por Alfonso Reyes y rayano en la onomatopeya y en la aliteración que, como los últimos versos Altazor, carece de semántica alguna. En La experiencia literaria, Reyes incluye un ensayo dedicado precisamente a analizar las jitanjáforas de Brull, donde distingue entre "impuras" y "puras". Las primeras son aquellas que resultan de la mezcla de dos palabras ya existentes pero que buscan un efecto sonoro que, sin embargo, poco o nada remiten a una referencia o significación concreta. Las "puras" son, por otra parte, aquel cuyo "léxico" es totalmente producto de la inventiva del autor. Son estas, las "puras" las que, en sentido estricto, estarían relacionadas con el fenómeno de la glosolalia. Con fines igualmente vanguardistas, el poeta cubano Mariano Brull hace uso de tal recurso:

Alveolea jitanjáfora cundre

ala alalúnea alífera

liris salumba salífera. 
Olivia olea olorife

alalai cánfora sandra

milingítara girófora

zumba, ulalindre calandra (cit. en Henríquez Ureña 90)

Si en Altazor la experiencia del vuelo resulta en una total violación del código gramatical y por ende, semántico, en el poema "Jitanjáfora" de Brull se juega a la simulación de una gramaticalidad: la morfología "suena" coherente; es un habla a la cual la lengua, a todas luces inventada, pretende aludir, como en una especie de vuelta de tuercas de la función poética de Roman Jakobson, a un mensaje sin que en realidad este termine por presentarse y el resultado no sea sino pura morfología y sonoridad, en suma, puro significante. Así, de esta representación estetizada del significante, puede deducirse, a partir de la disposición acentual, una cierta musicalidad que se concretiza en el aspecto del ritmo, donde el sentido ("el significado") queda más allá de la connotación: queda, pues de un modo radical, en la elisión total, ausente. Es un solo discurrir que no babla de nada sino de sí mismo, de su materialidad lingüística, de su acusticidad como causa última.

Este fenómeno consistente en un mero discurrir sonoro se halla, a su vez, enmarcado en la figura de un trance que, como discurso que lo contextualiza, posibilita un estado cuasihipnótico. Es, pues, tanto un éxtasis místico como un delirio patológico -si es que hay una división entre estos-, tanto una iluminación como una reverberación. En términos religiosos y místicos, la glosolalia es la manifestación del Espíritu, de una lengua angelical, una voz oculta que adquiere vigencia fónica y que, en su inextricable morfología, colinda con la irracionalidad. En términos puramente estéticos y seculares, como en los casos de Huidobro y de Brull, estamos ante un discurrir que, entre jitanjáforas y recurrencias acentuales que se asocian al ritmo, no resulta sino tributario de una concepción prelógica del mundo a partir de una canalización.

Asimismo, y a propósito de las vanguardias, la práctica del surrealismo conocida como "escritura automática" guarda cierta correspondencia con este fenómeno que redundaría, como se sabe, en 
la expresión de un yo libre de racionalidad y/o en la liberación del inconsciente. Aunque en una relación meramente tangencial con el surrealismo, Octavio Paz, quien no obstante confesó jamás practicar la "escritura automática," ha relatado que, al escribir Piedra de sol, redactó las primeras estrofas del poema (alrededor de treinta versos, todos ellos endecasílabos) automáticamente, como si alguien se las dictara (cit. en Santí 108). El resultado es un texto a un tiempo medido y libre, adentrado en esa visión compleja entre el ciclo del tiempo mítico y la linealidad de la razón moderna, la analogía y la ironía, que, al decir de cierta crítica, consiste en

una "mantrificación" en el alma del poeta, al mismo tiempo que obnubila los contenidos del poema, le presta un significado mayor: el de ser un conjunto de sonidos casi asignificantes, como una oración que transforma el hombre que la recita o lee más inserto en un timing recurrente. Un ritual verbal interno a los significados, de iniciación a una dimensión tanto poética como religiosa. (Costa 90)

Preponderancia de la forma sobre el contenido, del ritmo (metro y entonación) sobre el asunto, hay en Piedra de sol una versión mesurada de la glosolalia que no deja de revelar ese continum que se traza a partir de una pulsión que logra cristalizarse en la opacidad frenética del significante ${ }^{5}$. Ora en su versión mística, esotérica y religiosa, ora en su versión secular y estética, en los dos ámbitos no estamos sino frente a una metafísica del significante. Aún más, metafísica espiritualizada y metafísica estetizada. Si la edad clásica

${ }^{5}$ Para conocer, no tanto una perspectiva exclusiva de la analogía entre glosolalia y poesía, pero sí un enfoque donde se señala la preponderancia significativa del ritmo como eje de interpretación de dicho poema, véase: López Soto, Luis A., "Ritmo y sentido en Piedra de sol de Octavio Paz". Actas del XXXV III Congreso del Instituto Internacional de Literatura Iberoamericana. Ed. Enrique Cortez y Gwen Kirkpatrick. <http://www.iiligeorgetown2010.com/2/pdf/Lopez-Soto.pdf. Asimismo, véase: Andueza, María. "Ritmo y vuelta en Piedra de sol de Octavio Paz". Revista de la Universidad de México, no. 557, 1997, pp. 20-23. 
y la racionalidad moderna han resaltado el sentido, la significación, todo ese idealismo de los referentes y las referencias, en pos de una lógica de la significación y la comunicación, esta concepción de la poesía como voz prelógica despide cierta noción de significante como un elemento totalizador, pues, a diferencia del signo de Saussure en el Curso de lingüistica general, este significante no pasa por la dualidad del signo lingüístico. Es, pues, análogo a la lógica del símbolo, en cuya representación no hay escisión ni doble articulación. Este significante carece de doble. Es pura superficie y he ahí su potencia y su mecanismo seductor. Es un signo lingüístico cuyo significante es de segundo orden, ya que excede a las posibilidades del sentido. De este modo, su materialidad es una voz tan mágica como vacua, tan premoderna como vanguardista. Además de la jitanjáfora como recurso literario práctico se tiene el anagrama o la anafonía como categoría teórica en Saussure. Más allá del Saussure del Curso de lingüistica general, esta concepción de la poesía se halla también en una serie de textos hallados tras la muerte del lingüista suizo, en los que este analiza el fenómeno intrigante de ciertos anagramas a partir de poemas clásicos latinos, griegos, vedas y alemanes. El hallazgo fue presentado por Jean Starobinsky en Las palabras bajo las palabras: la teoría de los anagramas de Ferdinand de Saussure en 1971. En tal estudio, este otro Saussure atiende, según Jean Baudrillard, uno de sus críticos, a "un lenguaje sin expresión, más allá de las leyes, de los axiomas y de las finalidades que le asigna la lingüística; la forma de una operación simbólica del lenguaje, es decir, no de una operación estructural de representación a través de los signos, sino justamente a la inversa, de desconstrucción del signo y de la representación" (Baudrillard 221). En Anagramas, no hay sino repeticiones, asociaciones polifónicas, anafonías, formas mnemotécnicas del lenguaje que son, en suma, y para los intereses aquí perfilados, reveladores de una perspectiva teórica que ha agotado las posibilidades de la dualidad, y en la que la poesía, más que llegar a un límite de expresión, ha nacido ya con ese prerrequisito fundamental: la disposición fónica y la estructura métrico-rítmica en conjunción con cierta condición psíquica. 
Hay, además, entre Saussure y la glosolalia una relación interesante: si bien desde la perspectiva meramente lingüística y no tanto literaria, en La forma sonora de la lengua (1979) Roman Jakobson menciona el caso clínico de una mujer sonámbula (Muller/Smith) que padecía glosolalia y cuyos "discursos" delirantes presumiblemente parecían vincularse al sánscrito, lengua analizada por Saussure en Anagramas. El caso había sido registrado originalmente por Victor Henry, autor de Antinomies linguistiques (1896), obra que, a decir de Jakobson, inspiró "algunos conceptos del Cours saussuriano" (Jakobson, La forma sonora 206). Como se ha documentado, la paciente jamás había estudiado sánscrito, y pasmosamente Saussure logró reconocer patrones y rasgos del sánscrito. (Por otra parte, Jakobson confunde glosolalia con xenoglosia, fenómeno que figura también en el pasaje bíblico aludido y que pertenece al ámbito de la parapsicología, pues consiste en que el sujeto en trance profiere una lengua humana no aprendida. Véase la nota 2) Lo interesante de esto consiste en cómo Anagramas sería tanto un análisis como una retroproyección, es decir, la indagación de un sujeto que busca en el análisis y en el pasado sus propias obsesiones teóricas, difuminando así las fronteras entre sujeto y objeto.

Asimismo, otro acontecimiento teórico afín a la perspectiva general aquí asumida se observa en Henri Meschonnic, quien, a partir de sus estudios sobre el Antiguo Testamento y sobre la traducción poética en lo que llama Crítica del ritmo (1982), intenta asociar el ritmo a una precondición lingüística como numen poético: "Cuando el ritmo deviene el solo y único modo de expresión del pensamiento, sólo entonces hay poesía; es necesario que encierre en sí el misterio de un ritmo innato." (Citado por Hocevar 50) La idea de un ritmo innato de connotaciones universales nos lleva, sin embargo, a esa cierta imposibilidad para detectar y deducir concretamente sus mecanismos que, como ha de sospecharse, podrían consistir en algunos más que la mera jitanjáfora y el anagrama o la anafonía.

A partir de la perspectiva aquí tratada, no queda sino hacer una reducción fenomenológica que se vehicularía en la noción de significante: el punto de articulación entre ritmo como recurrencia y su efecto poético no es sino el de la sonoridad hipnotizante (jitanfa- 
jórica y anagramática), lo cual conlleva de algún modo a la glosolalia como forma semiológica y conductual. Así, la relación analógica entre poesía y don de lenguas se halla, pues, sobredeterminada por el carácter preponderantemente afectivo e irracional de la poesía.

La poesía comporta un lenguaje, un metalenguaje que, por analogía o por extensión, ha dado cuenta de una relación tan dinámica como sutil con lo sagrado. Es una relación ya muchas veces señala$\mathrm{da}$, aunque de vez en cuando revisitada, como se puede ver en los casos aquí expuestos: la exploración vanguardista que aspiraría a ser una inspiración descentrada, una nueva revelación que reconecta las fibras del poeta con las de un místico que "nada sabe" sino del trance de ser un mero canal de "otra voz"; la versión sublimada en la estetización de Piedra de sol de Paz y Altazor de Huidobro; y, en una visión aún más retrospectiva, los textos latinos, vedas, germanos y homéricos analizados por Saussure que comportarían a su vez esa latencia rítmica, para modelarse en la figura del rapsoda griego que magnéticamente recita a Homero.

En términos contemporáneos, la glosolalia como forma semiológica podría ser una poesía que es asimismo una vía de acceso, una invocación ciega a la nada concreta de la página en blanco. Ahí donde el lenguaje referencial, la sintaxis lógica y la semántica son suspendidos, descentrados, o, más aun, violados, queda sin embargo una estructura inmarcesible. Así como lo fue la gracia divina e irresistible para san Agustín, en términos seculares, el lenguaje es ya un don irresistible que hemos configurado incluso para clausularlo como en la figura de Vicente Huidobro, quien, según Paz, y como se ha expuesto, alegoriza el fracaso del lenguaje. No obstante, en su poema "Arte poética" Huidobro afirma que el poeta es un pequeno Dios, un creador, entonces ese don de lenguas otrora sagrado y ritual se ha desprendido de su núcleo simbólico para multiplicarse según la vocación retórica de cada sujeto lírico. La poesía sería, así, un don inefable e iniciático en tanto que creador y propulso de imágenes, pero, sobre todo, de un ritmo y de significantes. En algún punto indefinido de la tradición y conciencia occidentales, el lenguaje poético se ha vuelto un ejercicio centrífugo sin renunciar por ello a su carácter enunciativo, que dice sin decir, que dice más 
bien lo que alude y que refleja -como una intermitencia entre la pulsión de conciencia e inconsciencia- un fluido sin fuente (el lenguaje como demiurgo a la vez que objeto de creación) y que impide, sin embargo, renunciar a lo inefable.

\section{Obras citadas}

Baudrillard, Jean. El intercambio simbólico y la muerte. Monte Ávila Editores, 1980.

Beristáin, Helena. Diccionario de retórica y poética. Porrúa, 2000.

Costa, Horácio. "Piedra de sol: el título". Cuadernos Americanos, vol. 26, 1991, pp. 83-97.

Henríquez, Ureña Max. “Tránsito y poesía de Mariano Brull”. Boletín de la Academia Cubana de la Lengua, no. 7, enero-junio, 1958, pp. 49-69.

Huidobro, Vicente. Altazor o el viaje en paracaídas. Compañía Iberoamericana de Publicaciones, 1931.

Hocevar, Drina. "Música y lenguaje". Lengua y habla, no. 8, 2004, pp. 50-56.

García Berrio, Antonio. Teoría de la literatura: la construcción del significado poético, 2da. Edición. Cátedra, 1989.

Gil, Luis. Los antiguos y la inspiración poética. Guadarrama Ediciones, 1967.

Gili, Gaya Samuel. Estudios sobre el ritmo. Istmo, 1993.

Jakobson, Roman. Lingüistica y poética. Cátedra, 1988.

---. La forma sonora de la lengua, FCE, 1987.

Jung, Gustav Carl. El hombre y sus simbolos. Paidós, 1995.

La Santa Biblia anotada de Scofield. Editorial portavoz, 1982.

Fiorenza, Lipparini. "Poesía moderna y glosolalia". Revista Laboratorio, 2, 2010, 27 de agosto de 2016. www.revistalaboratorio. cl/2010/05/poesia-moderna-y-glosolalia.

Lotman, Yuri, La estructura del texto artístico. Istmo, 1988.

Paz, Octavio. El arco y la lira. Fondo de Cultura Económica, 1957.

---. "Hablar y decir. Leer y contemplar". Vuelta, no. 63, 1982, pp. 5-11. 
---. Sombras de obras. Fondo de Cultura Económica, 1983.

Platón. Obras completas, tomo 2. Edición de Patricio Azacarate, 1871.

Santí, Mario Enrico. El acto de las palabras. Fondo de Cultura Económica, 1997.

Starobinsky, Jean. Las palabras bajo las palabras: la teoría de los anagramas de Ferdinand de Saussure. Gedisa, 1971.

Toledo, Víctor. "Poética de la sincronicidad". Graffylia: Revista de la Facultad de Filosofía y Letras, vol. 2, no. 3, 2004, pp. 145-152. 